2019-02-14

\title{
Critical Dietetics and Sustainable Food Systems
}

Carlsson, L

http://hdl.handle.net/10026.1/15685

10.1007/978-3-030-03113-8

Springer

All content in PEARL is protected by copyright law. Author manuscripts are made available in accordance with publisher policies. Please cite only the published version using the details provided on the item record or document. In the absence of an open licence (e.g. Creative Commons), permissions for further reuse of content should be sought from the publisher or author. 


\title{
Chapter 7 \\ Critical Dietetics and Sustainable Food Systems
}

\author{
Liesel Carlsson, Kaye Mehta, and Clare Pettinger
}

\section{Aims of Chapter and Learning Outcomes}

In this chapter, we invite readers to consider a food system that is based on values where individual health, the health of the society (social system) and ecosystem health are of equal importance. With this as a lens, there is a clear need to move beyond the biosciences to consider transdisciplinary approaches as important for nutrition and dietetics in today and tomorrow's reality.

This chapter begins by briefly highlighting historical engagement of the nutrition and dietetics community with food system sustainability, before moving to define foundational concepts of sustainability in food systems and diets, from a systems perspective. It then provides some examples of how some of today's pressing nutritional challenges are sustainability challenges and examples of the interface between today's dietetics and food system sustainability. This chapter ends with a discussion on the role of nutrition and dietetic practitioners in food system sustainability and the needs and challenges for dietetic education to support that role.

At the end of this chapter, readers should be able to:

(i) Clearly understand the concept of sustainable food systems (SFS).

(ii) Describe some emerging roles for nutrition and dietetic professionals in contributing to food system sustainability.

\footnotetext{
L. Carlsson $(\varangle)$

Acadia University, Wolfville, NS, Canada

e-mail: liesel.carlsson@acadiau.ca

K. Mehta

Flinders University, Adelaide, SA, Australia

C. Pettinger

School of Health Professions (Faculty of Health and Human Sciences), University of

Plymouth, Plymouth, UK
} 
(iii) Consider engaging in deeper levels of inquiry about our responsibilities as a profession.

\section{A Brief History of Sustainability in Dietetics}

Issues of sustainability are not new to dietetics. One of the earliest (and best documented) "ecological nutritionists" was Ellen Swallow Richards. Richards was an early (human) ecologist, born in 1842. She worked as a chemist on issues such as water quality during an industrializing era and concerned herself with how that impacted public health. Richards was perhaps one of the first in North America to use the term "ecology", which "[she] saw as... neatly capturing her broad concerns for human-created environmental conditions and the health consequences for people living in those conditions" (Dyball and Carlsson 2017). As a woman in her day, despite a long career as a chemist, she was persuaded to throw passions for ecology into the domestic sciences, later called home economics, focusing more on managing the economy (a term with Greek roots meaning "household management") of the home. Subsequently, in many academic institutions, home economics evolved into the science of nutrition and dietetics, progressing from a practical focus on managing food as a family resource to an increasingly biomedical focus on the interrelationship between nutrients, health and disease.

Richards' ecological systems approach to home economics lays the groundwork for what Rebrovick would call "eco-dietetics" (Rebrovick 2015) or a dietetics that concerns itself with the interactions between eating and environmental, social, economic and political systems and celebrating food for the pleasure it provides. Here we briefly cover some central contributions to the emergence of an eco-dietetics discourse before unpacking some terms and key concepts.

In 1986, two American dietitians, Gussow and Clancy, proposed dietary guidelines for sustainability (Gussow and Clancy 1986). While this is often referred to as a pivotal publication proposing sustainability within the remit of dietetics, it reflected decades of civic activism on the responsibility of eaters to consider ecological sustainability. Though the ideas Gussow and Clancy put forth certainly did not lie dormant, biomedically driven dietetics dominated the focus of the profession for the following 20 years and, arguably, still does so today. In 2005, a framework referred to as the "New Nutrition Science Project" (Cannon and Leitzmann 2006) proposed reframing nutrition and dietetic research and practice around the interconnected biological, social and environmental dimensions of nutrition as a science (the term environmental here is used to mean the biological or natural world). The focus on the interconnected dimensions highlighted the need for a "systems approach" to addressing some of nutrition science's more intractable challenges, such as malnutrition, in all its forms. The international support for the New Nutrition Science Project (albeit European Union driven and focused) helped gain attention for the involvement of nutrition in global dialogues on food system sustainability. Ecological nutrition is a term also used to capture such a multidimensional and 
systems approach now broadly considered necessary to achieving sustainable diets (Mason and Lang 2017), which is now gaining policy traction in mainstream dietetics internationally, in Europe (British Dietetic Association 2017), North America (American Dietetic Association 2007; Carlsson et al. 2019); and Australia (Public Health Association Australia 2016). The concept is also emerging more broadly in public health as nations begin to incorporate aspects of sustainability to varying degrees. Qatar, Sweden and Brazil have taken radical steps to embed sustainability and social drivers and determinants into their national dietary guidelines. While dietetic curricula do pay some attention to the food system and sustainable eating, albeit to varying degrees of depth, the dominant focus of dietetic curricula today continues to be on biomedical aspects of nutrition and healthy eating, indicating that dietetic education is unlikely to equip graduates for work in the emerging field of sustainable eating. There is wider consensus that sustainability is an important issue in higher education and a need for all learners to acquire the knowledge and skills needed to promote sustainable development (United Nations General Assembly 2015). Despite this, growing community interest in sustainable eating, and calls for dietitians to bolster food system literacy (Palumbo 2016), barriers remain. Inadequate time in the curriculum (Harmon et al. 2011) and practical training opportunities, including knowledgeable preceptors (Wegener 2018), are two significant barriers to developing competence in this area. Investing in student training and professional development that is grounded in a clear understanding of the terms, concepts and current issues is essential for practitioners to play a strategic role in the future.

\section{Defining Key Terms and Concepts}

Sustainable diets (see glossary) is a term that has received increasing attention in the past decade, with roots in these historical eco-dietetic schools of thought and practice; sustainable diets contribute to and are supported by food system sustainability (Meybeck and Gitz 2017). The FAO and Bioversity International define sustainable diets as “... those diets with low environmental impacts which contribute to food and nutrition security and to healthy life for present and future generations. Sustainable diets are protective and respectful of biodiversity and ecosystems, culturally acceptable, accessible, economically fair and affordable; nutritionally adequate, safe and healthy; while optimizing natural and human resources" (Burlingame and Dernini 2012). The term sustainable diets places emphasis on the notion that human food choices (diets), and in particular those of "Western" and urban consumers, play a pivotal role in sustainable food systems.

Sustainable food systems is a broader, though clearly related, term that deemphasizes the eater while placing more weight on the complex network (sometimes described as a "food chain") of actors that produce, process and distribute food to consumers, often across vast geographic scales. The Food and Agriculture Organization (FAO) defines SFS as those that “... [deliver] food and nutrition secu- 
rity for all in such a way that the economic, social and environmental bases to generate food security and nutrition for future generations are not compromised" (HLPE 2017).

Both definitions are informed by the broadly accepted concept that sustainability rests on three main, interconnected systems - (i) the environmental, (ii) social and, in our current reality, (iii) economic. This "systems perspective" helps to see and articulate food systems as a complex network of actors and factors (Norberg and Cumming 2008) interacting with these three domains; it is an important perspective for dietetics because if the implicit values at stake are that we nourish our populations in a way that does not compromise future generations, then there is a clear need for dietetic practice to reflect the interrelationship between human diets and the environmental, social and economic impacts of such diets.

While dietetic practice has always put human health as the end goal (and thus the underlying value is that human health is paramount), a true systems perspective requires human health to be balanced against the important needs and limitations of other actors and factors in the system (e.g. other and all people; oceans, soil and air; animals; etc.).

To further challenge dominant dietetic frameworks, one way a systems perspective can be conceptualized is as "nested interdependencies". Fig. 7.1 illustrates the idea that the economy is nested within (dependent on) human society; similarly society is nested within the environment. Food systems are nested within all three systems and here illustrated as a constellation of various-sized actors and factors spanning those three systems.

This nested system perspective is not values-free; it does imply a hierarchy of importance between systems. It begs the question: "do the needs of the environment

Fig. 7.1 A nested systems perspective of food systems

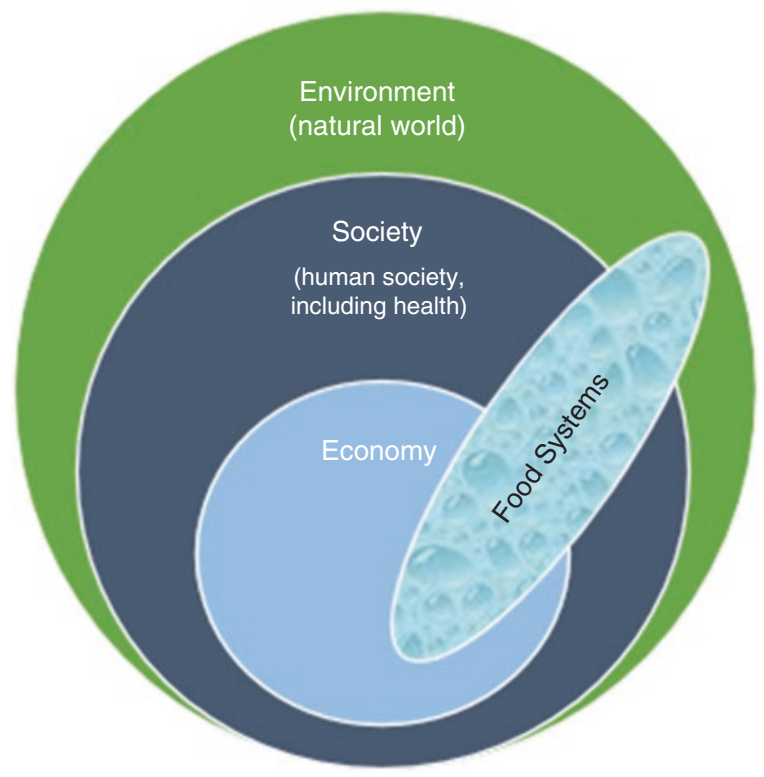


need to be prioritized above social and economic needs?" Further critical thought questions whether, in our current reality of over seven billion people on Earth, environmental integrity is not also dependent on human society being able to meet its own needs. That is to say, as humans we prioritize our needs at the expense of ecological integrity (e.g. we continue to use unsustainably high proportions of the Earth's arable land for human food production at the expense of other needs in the ecosystem). One could argue that, similarly, we assign disproportionate weight and power to the "needs" of the economic system, above those of the social and environmental systems (e.g. governing food systems for profit over equitable access to livelihoods, human health and ecosystems). A systems perspective allows us to see these nested systems (i.e. there is a hierarchy of dependencies) as interdependent (i.e. the systems are interrelated and co-dependent in complex ways).

A Critical Dietetics approach is framed by one that guides practice in a way that is knowledgeable and attentive to the needs and limitations that govern these nested systems.

\section{Unsustainable Nutrition}

Food systems are a driving force contributing to ill-health (IPES-Food 2017) and unsustainable conditions in our social and ecological systems.

\section{Food Systems, Ill Health and Inequality}

Food systems are contributing to social changes to eating. The food systems in developed countries, and to an increasing extent in developing countries, are largely corporatized and for-profit sitting squarely within capitalist and consumer-oriented societies (Konefal et al. 2005). Citizens are consequently exposed to many highly processed foods that are energy-dense and nutrient poor, which are also priced and marketed to encourage excessive consumption (Lang 2004). Together with social trends towards time pressure and search for quick, easy fixes, these highly processed foods offer convenient, tasty, albeit less healthy, options, which are seen in global dietary trends and concomitant health problems (Jabs and Devine 2006).

Direct relationships between "Western" diets (and the food systems that perpetuate them) and poor health have been well recognized for over 20 years (Drewnowski and Popkin 1997). Western diets are synonymous with diets excessively high in free sugars, salt, fats, meats, and high levels of processing. They are ubiquitous in industrialized nations and, increasingly, in industrializing nations. Transition towards more Western diets is well known to contribute to diet-related diseases, in particular higher risk of type II diabetes, cardiovascular diseases, hypertension (Drewnowski and Popkin 1997) and some cancers (Bouvard et al. 2015). 
While over half the world struggles with diet-related, chronic disease, there are inequalities in food access (Lang 2015). We generate more than enough food to feed our current population, just over 7 billion (United Nations 2017), yet approximately 800 million people in the developing world are undernourished, and about 2 billion are deficient in key micronutrients (FAO et al. 2017). Chronic or periodic undernutrition can lead to child stunting or wasting, respectively, which can have intergenerational consequences on the attainment of potential growth and development, with negative social and economic impacts. Deficiency in key micronutrients can lead to acute conditions including blindness and anaemia even in adults. Consequently, the world is facing multiple forms of malnutrition (overnutrition, undernutrition and micronutrient deficiencies) that each carry health burdens. Industrializing countries are struggling with pandemic levels of each, often driven by the nutrition transition, towards Western diets.

\section{Food Systems and Environmental Degradation}

A growing human population is increasing demands on our food systems, and the same time, food systems are stressed by environmental degradation of global ecosystems. But our current food system is also contributing to compromised ecosystem resources and services on which our ability to produce food depends (Tilman and Clark 2014). An estimated 20-50\% of greenhouse gas emissions (GHGe) are attributed to agricultural activities (Garnett 2011; GRAIN 2011). The bulk of research demonstrates that diets high in red meat (especially from ruminants: cows, sheep, etc.) have a substantial impact on GHGe, even when accounting for variability in production/grazing approaches (Garnett et al. 2017). These GHGe are of central concern to climate change scientists who confirm and predict that climate change is already and will continue to impact our ability to produce food Diets that include higher amounts of animal-sourced foods (commonly meats and dairy products) also use significantly more water (Vanham et al. 2013) and require more land for both pasture and feed (e.g. soy) than would diets with proportionately higher amounts of plant-based foods (e.g. various forms of vegetarian and "flexitarian" diets). With agriculture already using $92 \%$ of the global annual average water (Hoekstra and Mekonnen 2012) and land use for human food production at $60 \%$ of available land, there is little room to "grow".

These three examples, GHGe, water and land use, provide a meaningful yet incomplete snapshot of the magnitude of food system-related environmental impacts. Taken together with the social and human health-related impacts in the previous section, it becomes clear that implementation of dietary solutions to the tightly linked diet-environment-health trilemma is a challenge on a global scale (Tilman and Clark 2014) requiring a "systems" approach (iPES Food 2015).

With possible co-benefits emerging, more sustainable nutrition lies at the intersection of public health, environmental health and the business of food (Garnett 2014). Food is a massive industry, and the many key players involved have very 
different interests. There is a call for stronger multi-sector leadership in championing a sustainable ecological approach to food systems (City University of London Centre for Food Policy 2018). Nutrition and dietetic professionals are in a strong position to participate in leading food system sustainability discourse and practice and have a clear role in safeguarding food and nutrition priorities. However, as is discussed in the next section, case examples from the UK, Australia and Canada show that there is a need for a better understanding of their strategic role, and rolespecific priorities need to be more strongly articulated. A clearer picture of the professional role will inform training and professional development needs (Pettinger 2018).

For the past number of decades, nutrition and dietetic professionals globally have gained competency working to maximize the diet-health outcomes domain and applying Social Determinants of Health lens to address human health. However, despite the professional history of environmental engagement, addressing ecological determinants of health (e.g. CPHA*ACSP 2015) is mostly considered "out of scope" for health practitioners including dietitians. This is influenced by the dominant neoliberal politics of many countries (including the UK, Australia and Canada), which privilege an individualist focus over a structural (systems) one (Jessop 2016).

To guide nutrition and dietetic education, practice and scholarship, a conceptual framework that guides a transformative curriculum around SFS and diets is needed.

\section{Sustainable Nutrition in Practice}

In 2016, the International Congress of Dietetics adopted the theme of 'going to sustainable eating', demonstrating a growing level of interest among dietitians around the globe (and in particular in the European countries, who hosted the Congress). Despite weak and often ad hoc emphasis on the key concepts and issues in education, practice and scholarship in most countries, many dietitians are applying this lens to practice, stepping into non-traditional roles and leadership opportunities to forward this agenda. This section outlines examples from the field in the UK, Australia and Canada, outlining the current situation, (educational) action and outcome for each case presented.

\section{The UK}

In the UK, a recently updated sustainable diet policy statement by the British Dietetic Association (BDA) has stated that it believes the profession should be leading discussions on how food behaviours can affect both health and the environment (British Dietetic Association 2017). Dietitians, the policy states, are in a strong position to combine healthy eating messages and sustainable dietary advice. This aligns with the newly upgraded UK Eat Well Guide, which mentions sustainability in 
relation to meat and fish consumption. This BDA policy is accompanied by a practical "toolkit" to support dietitans in practice (BDA, 2018) recently co-created by the BDA with an active group of "special interest" dietitians/nutritionists. Many UK dietitians and nutritionists are already engaged in sustainability advocacy across a range of sectors, for example, working with local food partnerships, a movement that is currently driven by the 'Sustainable Food Cities (place based) Network'. Similarly, some UK dietitians and nutritionists have been involved in sustainabilitydriven settings-based award schemes, in schools and care home settings, which have seen positive outcomes. Notwithstanding, positive systems-level activity and investment in dietetic student training is important.

Sustainability is being addressed in the dietetic curriculum at the University of Plymouth. An exploratory pedagogic workshop was run with final year dietetic students as part of their Public Health Nutrition module in October 2016 (Pettinger et al. 2018). Student participants ( $n=26)$ attended a 2-h workshop, which included: (i) delivery of learning materials by a sustainability specialist dietitian, (ii) basic interactive survey, (iii) group work (discussing potential roles of dietitians in different settings) and (iv) plenary discussion.

The question template was designed based on previous research suggesting a lack of dietetic knowledge about sustainability (Webber and Sarjahani 2011) and supported by responses gathered from a LinkedIn 'straw poll' carried out in spring 2016 asking UK dietitians $(n=9)$ about their broad views on sustainability. This poll indicated above all a lack of definitional clarity around the term 'sustainability' for dietitians. Qualitative feedback was obtained from participating students who demonstrated a reasonable understanding of sustainable eating and could articulate practical roles for dietitians in promoting sustainability, for example, "liaising with [hospital] catering team and minimising food/supplement waste" (student 10). They were enthusiastic to learn about sustainable eating and felt that it should be more strongly embedded in the dietetic curriculum, for example, "it should just be throughout every subject ... so in the 'Dietetics in Practice' module, when we're talking about practical food advice, get us thinking about sustainability, e.g. less meat" (student 5). The views of the students concur with general UK student views (Cotton and Alcock 2013) including that a sustainability lens is needed for curricula that are 'fit for the future'Goodman and East 2014). Interactive participatory workshops align well with adult learning theories for healthcare professionals (Taylor and Hamdy 2013). They have been documented to motivate and energize students, empowering them in transformative learning experiences (Seale 2013). More research is needed to support this educational goal to enable students to be better prepared for the diversity of their future practice. This research is ongoing, currently investigating nutrition/dietetic students' environmental attitudes and how these relate to their actual sustainability practices and behaviours. 


\section{Australia}

The Dietitians Association of Australia and the Australian Public Health Association (PHAA) have interest groups that engage dietitians and nutritionists on nutrition and sustainability matters. Both groups focus on information sharing, professional development and advocacy. The PHAA has developed explicit policy statements which it uses for advocacy purposes. Public health dietitians advocated for inclusion of sustainable eating into the latest version of the Australian Dietary Guidelines, and, while this is not explicit in the key messages of the guidelines, it nevertheless informed the food modelling and was inserted in the appendices (NHMRC 2013). Notwithstanding professional interest groups, the application of sustainable eating into professional practice by Australian dietitians and nutritionists is largely individualized and voluntary because sustainable eating is not structurally embedded within government food-related policies. At the time of writing this chapter, (2018), Australian governments at all levels have reduced their investment in health promotion and prevention, thereby further marginalizing nutrition sustainability work (Moodie et al. 2016).

Flinders University of South Australia has had a long tradition of critically investigating the food system in its nutrition and dietetic curriculum. It is assumed that this topic is also addressed by other Australian universities. Apart from student education, in 2016, Flinders University academics from Nutrition and Dietetic and Public Health have trialled community education on food systems. They developed a 2-week online course, Food System Matters (FSM), which examined the food system through three lenses: environmental sustainability, fairness and equity and health and nutrition. The curriculum was delivered using a combination of text, videos, images, quizzes, activities, critical thinking questions and discussion forum. The course was delivered through Flinders Learning Online (FLO), Flinders University's internal education platform which limited the trial to staff and students of the university. The education program was evaluated for effects on knowledge about the food system literacy and attitudes to food choices for health (Mehta 2017). Forty-seven staff and students participated in the course and were randomly allocated into one of two groups - (1) Intervention and (2) Control and Intervention. Knowledge about the food system improved significantly for both Intervention groups from baseline $(p<0.001)$ compared to the Control group $(p=0.00)$. Attitudes to sustainable food choices improved significantly for both Intervention groups from baseline $(p<0.001 ; p=0.005)$ but, however, were not statistically significant when compared to the Control group ( $p=0.065 ; p=0.43)$, although in a positive direction.

Following the quantitative evaluation, a qualitative evaluation was undertaken in 2017, of FSM participants' engagement in sustainable eating behaviours and food system education. Nine tertiary-educated staff participated in the semi-structured interviews. The majority of participants were found to be in the later stages of health behaviour change, in other words, action and maintenance according to the transtheoretical model of behaviour change (Glanz et al. 2015). The FSM course 
consequently reinforced their existing beliefs and practices about sustainable eating. Participants were primarily motivated by ethics and benefits to broader society which aligns with a US study by Alkon (2008) but contradicts other studies which emphasized values of health, quality, freshness and taste (Hoek et al. 2017). The challenge for community food system literacy is common to all types of health education, namely, to reach those people who are less committed to change by dint of being in the contemplation and pre-contemplation stages of health behaviour change (Hirvonen et al. 2015). Even for the committed participants, time was reported as a barrier to their engagement, and time is known to be a common barrier to participation in health promotion (Linnan et al. 2001).

Food system literacy offers a novel approach to engage the public in a broader discourse on food and society (Lang 2005). Food system literacy has the potential to yield health benefits because food consumption behaviours oriented towards social and environmental sustainability will by default be healthier choices, favouring less meat and processed foods and more locally produced fruits and vegetables (Friel et al. 2014). Notwithstanding the positive outcomes of this pilot community education program, it is not supported by government policy or funding, thereby providing dietetic graduates with few opportunities to hone their skills in this subject area.

\section{Canada}

In Canada, Dietitians of Canada is beginning to make strategic steps to support Canadian dietitians to be leaders in SFS. In 2015, the Board of Directors of Dietitians of Canada (DC) sets a strategic direction to raise the profile of dietitians as leaders in SFS that promote healthy diets and that involved building a common understanding of what this means, such that dietitians can participate in intersectoral innovations and advocacy. This strategic direction led DC to collaborate on research that began to fulfil these needs and to initiate a SFS Leadership Team to support DC in advocacy and action.

With partners from Acadia University (Canada) and Blekinge Institute for Technology's Department of Strategic Sustainable Development (Sweden), in 2017 DC engaged in research to create common understanding of what we mean when we say "sustainable food systems" and begin to set a course for action. In the research, members of DC were invited to participate in an iterative dialogue through a modified Delphi inquiry process; Carlsson et al. 2019) which asked dietitians to envision a sustainable food system in Canada, describe current barriers and supports, describe high-leverage actions as well as suggest indicators to track progress. This research was in part established to fulfil the needs of the DC SFS Leadership Team, which is currently focused on three key areas: policy and advocacy, education and communication.

The outcomes of the research and the Leadership Team are tied. Of the 4885 DC members invited to participate in the research, over 50 dietitians participated in 
dialogue over the course of 6 months. Outcomes suggested that high-leverage action areas for dietitians include education, organizational infrastructure/policies and public policy, and key action approaches highlighted the need for reflexive and collaborative approaches (Carlsson et al. 2019). Central to the aim of this chapter was that participating dietitians highlighted the need for education for SFS literacy among dietetic students, professionals and the public. Participating dietitians made it clear that while food systems and sustainability are listed as foundational knowledge statement requirements to which all accredited dietetics programs in Canada must adhere (Partnership for Dietetic Education and Practice 2014), dietitians are generally not adequately trained to step into multisectoral innovation for SFS. They identified a need for stronger integration of SFS in dietetic education and training, along with post-graduate professional development opportunities and resources to guide practice, such that dietitians are well equipped to lead the development of programming and policy that will strengthen public SFS literacy.

The need for such education is one of the areas the Leadership Team has chosen to focus on, who, at the time of writing, have developed an evidence review on plant-based diets and the environment, which will form the basis of future practice resources, and discussions at national conference on setting strategic directions, speaking about sustainability in language accessible to the audience, plant-based diets in institutions and the role of dietitians in sustainable diets. The Leadership Team has also been actively advocating for national food policy that applies a systems lens, for example, through explicit messages about sustainability in national food guidance.

While there is still much work to be done, the member-informed and member-led approach that Dietitians of Canada is taking shows promise for increasing interest in SFS as a practice area and competence to lead innovations for food system sustainability.

These three case study examples illustrate movement (in the right direction) globally in this essential field for dietitians. Yet all three highlight obvious educational gaps that need to be urgently filled, if the future dietetic workforce is going to be adequately equipped with the skills required to contribute to SFS.

\section{Moving Forward}

\section{What Is the Role for Dietitians?}

Dietitians have an important role in advising the public around sustainable diets as well as addressing the many challenges of building a more resilient and sustainable food system. In the US, this role is recognized and defined by the publication of the professional position paper 'Standards for Professional Performance for Registered Dietitian Nutritionist in Sustainable, Resilient, and Healthy Food and Water Systems' (Tagtow 2014). 
Given some of the evidence reviewed under the section on Unsustainable Nutrition, linking food systems to human health, food culture and environmental degradation and given the globally interdependent nature of these complex issues, the role of nutrition professionals is more significant and pressing than ever, and international coordination is advisable. But for this to happen, there needs to be an agreement from international and national dietetic/nutrition professional bodies that sustainability/food system literacy is an essential part of education, training and practice.

The case examples in this chapter illustrate that there are several key leverage points where nutrition and dietetic professionals can make meaningful, systematic change: (1) advocacy and public policy, (2) influencing organizational policies and structures and (3) education and training for both nutrition professionals as well as the public. In this section we discuss the third leverage point - education and training - and explore emerging barriers and supports. Given the reciprocal relationship of influence between curricula in accredited dietetics programs and evidence-based professional practice, the below discussion mingles the opportunities and challenges for dietetic students and professionals alike.

\section{The Need for Education and Training}

There are international and national-level calls for general sustainability education to meet the United Nations Sustainable Development Goals, as well as specific calls related to health professionals. Currently dietetic education and training does not equip present and future professionals for leadership roles in SFS and diets (Pettinger). Harmon et al. (2011) has highlighted the need to develop foundational educational knowledge and skill competencies for nutrition professionals related to food systems and sustainability, and it has been described as an obligatory professional growth area by Wegener (2018).

There is emerging evidence that integration of even short-term sustainability education into formal education can be an effective tool for public education, as illustrated by the Australian case example, as well as dietetic trainees. Innes et al. (2018) looked at the integration of 'environmental literacy' in undergraduate nutrition programs in the USA and found that a 2 -week food sustainability module improved student sustainable literacy levels. These two examples support the utility of formalized sustainability education, in particular in concentrated modules that may be easier and faster to implement than holistic curriculum changes, and an opportunity for dietetic education and training, as well as continued professional development models.

However, a Critical Dietetics approach would challenge dietetic educators to apply a more systematic approach - using a 'sustainability lens' through which to view the development of nutrition and dietetic education, practice and scholarship that are: 
- Grounded in a clear understanding of the terms, concepts and current issues

- Knowledgeable and attentive to the needs, limitations and interdependencies of the economic, social and environmental systems

- Guided by a conceptual framework that facilitates critical analysis of complex systems approaches

\section{The Approach}

A Critical Dietetics approach would also be reflexive - moving forward with new ways of thinking about evidence - and collaborative, with expanded notions of what other expertise is relevant to our work.

New ways of thinking about evidence are necessary. There are some nutrition professionals already championing leadership in this area, who recognize the paradigm shift that accompanies the advancing wave of complexity thinking which emphasizes 'non-linear' contexts and promotes 'systems thinking' approaches to problem-solving. There is a fundamental challenge, however, for nutrition/dietetic education, which has its traditions in biomedical models of evidence-based practice relying on mainly reductionist research paradigms. Extending the remit of evidencebased practice to embrace more relational models of critical thinking is needed in all nutrition training and practice. The Critical Dietetics movement "seeks to explore new ways of framing how we educate, practice and research in dietetics, i.e., the professional discipline of nutrition" (Gingras et al. 2014). This postulates the need to expand traditional theoretical frameworks beyond current conventional thinking. Nutrition professionals, therefore, should be bringing critical perspectives on food and health (in their broadest sense) to sustainability.

Dietitians are accustomed to collaborating in multidisciplinary teams (e.g. other health professionals, community services, urban planning, etc.). In the area of food systems sustainability, collaborations with less familiar sectors can present new challenges and opportunities, perhaps even conflicts of interest, if, for example, work is being carried out with the private sector (Johnston and Finegood 2015). Regardless, an openness to knowledge, evidence and experience together with nontraditional knowledge domains and colleagues is important to meaningful learning and progress. We cannot be experts in all the relevant socioecological domains; but by learning to learn from and collaborate with others, practitioners and members of the public may approach a more reflexive, systems approach. 


\section{What Are the Barriers?}

While arguing for systematic integration of a critical sustainability lens in dietetic education, and practice, we recognize that there are known barriers, which need to be acknowledged. These can be categorized as sociopolitical, professional and institutional.

\section{Sociopolitical Barriers}

The governments of Australia, the UK and Canada can be described as neo-liberal, to the extent that economics is at the heart of the conduct of government; free markets are perceived to be essential to the success of the sovereign state and its population (Dean 2010). Neo-liberalism maintains the governance role of the state at a level which is moderate, frugal and prudent. Not unexpectedly, in neo-liberal societies, the food industry exerts considerable influence on matters of governance (such as national dietary guidance), upholding its profit-making interests even when this conflicts with public interest. Citizens in neo-liberal societies are considered to be autonomous individuals, with the freedom to choose; however, these rights come with responsibilities for self-regulation, e.g. to make food choices that contribute to wellbeing (Bauman, 2009). Dietitians, as the experts using disciplinary knowledge and technologies, reinforce food industry-informed, publicly encouraged (through, e.g., dietary guidance) behaviours through education, monitoring and surveillance of citizens. In this way, dietetics has adapted uncritically to the dominant individualistic discourse and evolved to work with the autonomous, self-regulating individual, rather than problematizing structures or systems. Further, this societal discourse presents a challenge as the public too is embedded in this discourse (Mehta 2013).

\section{Professional Barriers}

While there is evidence of growing interest and engagement, there are mixed levels of competence. Some researchers have found that there appears to be a reasonable understanding of the broad conceptual definitions of sustainable eating, while others indicate a lack of knowledge, practical skills and competence to work confidently on SFS. Predictably, a small sample of student dietitians reported that they do not have the confidence in their knowledge to apply it effectively (Pettinger et al. 2018), even though they wanted to engage with the topic.

This is exacerbated by the lack of clarity on the complex terms and concepts and reinforced by apparent conflicting perspectives about communicating information on sustainable diets and eating. Consumers are influenced by nutrition and health messages from a range of different sources, some of them with conflicts of interest, for example, between profit and consumer wellbeing and social or environmental outcomes. The sustainable diet agenda is likely to add to the plethora of messaging, 
and potentially confuse consumers further (Mason and Lang 2017), and thus an opportunity for dietitians, who are skilled in effective public education, to engage.

Furthermore, in the UK, the relevance of SFS and diets is not uniformly clear across different population groups (e.g. vulnerable groups) yet alone in the various dietetic practice settings and concern that these priorities might conflict with nutrition therapy priorities. Perceived lack of relevance and cultural authority to act will be a barrier to meaningful integration of a SFS lens in how dietitians work with interns, colleagues (including those from other disciplines) and the public to frame problems.

\section{Institutional Barriers}

In most countries that offer accredited programs in universities, dietetic curricula are driven by professional standards. This offers significant advantages in terms of the credibility of the profession. But as discussed previously, one fundamental challenge is that these professional standards are shaped by scientific evidence rooted in biomedical models of evidence analysis, as well as neoliberal governance models, which don't lend themselves well to complex socioecological challenges such as unsustainable nutrition.

Furthermore, practical issues such as time and space in the curriculum are perceived as significant barriers to expanding teaching on food systems and sustainability. Despite universal acknowledgement that a wide range of skills and knowledge are required to create an action-orientated sustainability-literate graduate body, many of these skills and attributes are inadequately addressed in dietetic curricula because the already tight curricula prioritize competency specifications of professional dietetic bodies.

\section{Conclusion}

While the barriers are many, the case examples in this chapter highlight examples of sustainability education being incorporated into dietetic and public education as well as practice. These demonstrate the potential of emerging examples of the application of a sustainability lens in dietetic education, the use of formal education approaches, settings-based motivational programs for public education on food systems sustainability as well as efforts on the part of professional dietetic associations working to embed these issues into the organizational culture. To build on these, and other successes, there is a need for a Critical Dietetics approach: one that is based on values where individual health, the health of the society (social system) and ecosystem health are of equal importance; one that moves beyond the biosciences to a conceptual framework that guides transdisciplinary and transformative education for nutrition students, practitioners and the public. 


\section{Assignments}

Level 1: Understanding key concepts.

Compile your own glossary of terms based on any concepts that are unfamiliar to you (try to make them evidence based where possible).

Level 2: Reflect on and apply key concepts in a new context.

Reflect on your experience as a nutrition and dietetics student thus far. In what ways could a Critical Dietetics approach to SFS and diets have been integrated into some of your learning opportunities (course work, practical training, etc.)?

Imagine yourself practising within the following dietetic/nutrition settings. Describe opportunities to apply sustainable diet/food system thinking to your role: E.g. of roles (public health, industry, community, clinical, media or other role that is emerging or relevant in your home country)?

Level 3: Analyse and critique the concepts.

Moving beyond the focus on educational aspects, write a critical analysis of the nutrition professional/dietitian roles in (1) advocacy and public policy and (2) influencing organizational policies and structures.

\section{Definition of Keywords and Terms}

Ecological nutrition

Sustainable diets

Sustainable food systems
A term used to capture such a multidimensional and systems approach now broadly considered necessary to achieving sustainable diets.

The FAO and Bioversity International define sustainable diets as " $\ldots$ those diets with low environmental impacts which contribute to food and nutrition security and to healthy life for present and future generations. Sustainable diets are protective and respectful of biodiversity and ecosystems, culturally acceptable, accessible, economically fair and affordable; nutritionally adequate, safe and healthy; while optimizing natural and human resources".

The Food and Agriculture Organization (FAO) defines SFS as those that "... [deliver] food and nutrition security for all in such a way that the economic, social and environmental bases to generate food security and nutrition for future generations are not compromised" (HLPE 2017). 


\section{References}

Alkon AH (2008) From value to values: sustainable consumption at farmers markets. Agric Hum Values 25:487-498. https://doi.org/10.1007/s10460-008-9136-

Bauman Z (2009) Does Ethics Have a Chance in a World of Consumers. Harvard University Press, Cambridge, UK

Beauman C, Cannon G, Elmadfa I et al The principles, definition and dimensions of the new nutrition science. Public Health Nutr 8:695-698

Bouvard V, Loomis D, Guyton KZ et al (2015) Carcinogenicity of consumption of red and processed meat. Lancet Oncol 16:1599-1600. https://doi.org/10.1016/S1470-2045(15)00444-1

British Dietetic Association (2017) British Dietetic Association Policy Statement: Sustainable Diets

British Dietetic Association (2018) One Blue Dot: Environmentally Sustainable Diet Toolkit/Reference guide for dietitians https://www.bda.uk.com/professional/resources/ environmentally_sustainable_diet_toolkit_-_one_blue_dot

Burlingame B, Dernini S (2012) Sustainable diets and biodiversity: directions and solutions for policy, research and action. Nutrition and consumer protection division, food and agriculture organization, Rome, Italy

Cannon G, Leitzmann C (2006) The new nutrition science project. Scand J Food Nutr 50:5-12

Carlsson L, Callaghan E, Broman G (2019) How can dietitians leverage change for sustainable foodsystems in Canada? Can J Diet Pract Res.

City University of London Centre for Food Policy (2018) Food Research Collaboration. http:// foodresearch.org.uk/about-us/. Accessed 31 Jul 2018

Cotton DR, Alcock I (2013) Commitment to environmental sustainability in the UK student population. Stud High Educ 38:1457-1471. https://doi.org/10.1080/03075079.2011.627423

CPHA*ACSP (2015) Global change and public health: addressing the ecological determinants of health. Canadian Public Health Association, Ottawa, ON

Dean M (2010) Governmentality: power and rule in mondern society, 2nd edn. Sage Publications, London

Drewnowski A, Popkin BM (1997) The nutrition transition: new trends in the global diet. Nutr Rev 55:31-43

Dyball R, Carlsson L (2017) Ellen Swallow Richards: mother of human ecology? Hum Ecol Rev 23:17-28

FAO, IFAD, UNICEF, et al. (2017) The State of Food Security and Nutrition in the World, 2017. Building resilience for peace and food security. Food and Agriculture Organization of the United Nations, Rome, FAO

Friel S, Barosh LJ, Lawrence M (2014) Towards healthy and sustainable food consumption: an Australian case study. Public Health Nutr 17:1156-1166. https://doi.org/10.1017/ S1368980013001523

Garnett T (2011) Where are the best opportunities for reducing greenhouse gas emissions in the food system (including the food chain)? Food Policy 36:S23-S32. https://doi.org/10.1016/j. foodpol.2010.10.010

Garnett T (2014) Three perspectives on sustainable food security: efficiency, demand restraint, food system transformation. What role for life cycle assessment? J Clean Prod 73:10-18. https://doi.org/10.1016/j.jclepro.2013.07.045

Garnett T, Godde C, Muller A, et al. (2017) Grazed and confused. Food climate research network

Gingras J, Asada Y, Fox A et al (2014) Critical Dietetics: a discussion paper, vol 2, pp 2-12

Glanz K, Rimer BK, Viswanath K (2015) Health behavior: theory, research, and practice, 5th edn. Jossey-Bass, San Francisco, CA

Goodman B, East L (2014) The "sustainability lens": a framework for nurse education that is "fit for the future". Nurse Educ Today 34:100-103 doi: 0.1016/j.nedt.2013.02.010

GRAIN (2011) Food and climate change: the forgotten link. https://www.grain.org/article/ entries/4357-food-and-climate-change-the-forgotten-link. Accessed 16 Jun 2016 
Gussow JD, Clancy KL (1986) Dietary guidelines for sustainability. J Nutr Educ 18:1-5

Harmon A, Lapp JL, Blair D, Hauck-Lawson A (2011) Teaching food system sustainability in dietetic programs: need, conceptualization, and practical approaches. J Hunger Environ Nutr 6:114-124

Hirvonen N, Korpelainen R, Pyky R, Huotari M-L (2015) Health information literacy and stage of change in relation to physical activity information seeking and avoidance: a population-based study among young men. In: Proceedings of the 78th ASIS\&T Annual Meeting. American Society for Information Science, Silver Springs, MD, USA

HLPE (2017) Nutrition and Food Systems. A report by the High Level Panel of Experts on Food Security and Nutrition of the Committee on World Food Security. Committee on World Food Security, Rome

Hoek A, Pearson D, James S et al (2017) Shrinking the food-print: a qualitative study into consumer perceptions, experiences and attitudes towards healthy and environmentally friendly food behaviours. Appetite 2017:117-131. https://doi.org/10.1016/j.appet.2016.09.030

Hoekstra AY, Mekonnen MM (2012) The water footprint of humanity. Proc Natl Acad Sci 109:3232. https://doi.org/10.1073/pnas.1109936109

Innes S, Shephard K, Furnari M et al (2018) Greening the curriculum to foster environmental literacy in tertiary students studying human nutrition. J Hunger Environ Nutr 13:192-204. https:// doi.org/10.1080/19320248.2016.1255693

iPES Food (2015) The new science of sustainable food systems: overcoming barriers to food systems reform

IPES-Food (2017) Unravelling the Food-Health Nexus: addressing practices, political economy, and power relations to build healthier food systems. The Global Alliance for the Future of Food and IPES-Food

Jabs J, Devine C (2006) Time scarcity and food choices: an overview. Appetite 47:196-204

Jessop RD (2016) The handbook of neoliberalism: the heartlands of neoliberalism and the rise of the Austerity State, S Springer, K Birch \& L McLeavy. Routledge

Johnston L, Finegood D (2015) Cross-sector partnerships and public health: challenges and opportunities for adressing obesity and noncommunicable diseases through engagement with the private sector. Annu Rev Public Health 18:255-271. https://doi.org/10.1146/ annurev-publhealth-031914-122802

Konefal J, Mascarenhas M, Hatanaka M (2005) Governance in the global agro-food system: backlighting the role of transnational supermarket chains. Agric Hum Values 22:291-302

Lang T (2004) Food industrialisation and food power: implications for food governance. Dev Policy Rev 21:555-568. https://doi.org/10.1111/j.1467-8659.2003.00223.x

Lang T (2005) Food control or food democracy? Re-engaging nutrition with society and the environment. Public Health Nutr 8:730-737

Lang T (2015) In: Earthscan, from Routledge (ed) Food wars: the global battle for mouths, minds and markets, 2nd edn, LondonlNew York

Linnan L, Sorensen G, Colditz G et al (2001) Using theory to understand the multiple determinants of low participation in worksite health promotion programs. Health Educ Behav 28:591-607

Mason P, Lang T (2017) Sustainable diets: how ecological nutrition can transform consumption and the food system. Routledge, New York

Mehta K (2013) Parents' and children's perceptions of food and beverage marketing to which children are exposed. Flinders University

Meybeck A, Gitz V (2017) Sustainable diets within sustainable food systems. Proc Nutr Soc 76:111. https://doi.org/10.1017/S0029665116000653

Moodie AR, Tolhurst P, Martin JE (2016) Australia's health: being accountable for prevention. Med J Aust 205:223-225. https://doi.org/10.5694/mja15.00968

NHMRC (2013) Australian dietary guidelines. National Health and Medical Research Council, Canberra

Norberg J, Cumming GS (2008) Complexity theory for a sustainable future. Columbia University Press, New York 
Palumbo R (2016) Sustainability of well-being through literacy. The effects of food literacy on sustainability of well-being. Agric Agric Sci Procedia 8:99-106. https://doi.org/10.1016/j. aaspro.2016.02.013

Partnership for Dietetic Education and Practice (2014) Standards - PDEP. https://www.pdep.ca/ tools/standards.aspx. Accessed 13 Jun 2018

Pettinger C (2018) Sustainable eating: opportunities for nutrition professionals. Nutrition Bulletin

Pettinger C, Atherton E, Miller W (2018) Engaging student dietitians in 'sustainability principles' throughout the curriculum: an exploratory pedagogic workshop. J Nutr Diet 31:44

Position of the American Dietetic Association (2007) Food and Nutrition Professionals Can Implement Practices to Conserve Natural Resources and Support Ecological Sustainability. Journal of the American Dietetic Association 107 (6):1033-1043Mehta K (2017) Promoting community awareness of the food system: benefits and risks. Dietit Assoc Aust SA Branch, Professioanl development workshop

Public Health Association Australia (2016) Public Health Association of Australia: Policy-at-aglance - Ecologically Sustainable Population for Australia Policy

Rebrovick T (2015) The politics of diet: "eco-dietetics," neoliberalism, and the history of dietetic discourses. Polit Res Q Salt Lake City 68:678-689

Seale J (2013) Doing student voice work in higher education: an exploration of the value of participatory methods. Br Educ Res J 36:995-1015. https://doi.org/10.1080/01411920903342038

Tagtow A (2014) Academy of Nutrition and Dietetics: Standards of professional performance for Registered Dietitian Nutritionists (Competent, Proficient, and Expert) in Sustainable, Resilient, and Healthy Food and Water Systems. J Acad Nutr Diet 114:475-488.e24

Taylor D, Hamdy H (2013) Adult learning theories: implications for learning and teaching in medical education: AMEE Guide NO 83. Med Teach 35:1561-1572. https://doi.org/10.3109/0142 159X.2013.828153

Tilman D, Clark M (2014) Global diets link environmental sustainability and human health. Nature 515:518-522. https://doi.org/10.1038/nature13959

United Nations (2017) World Population Prospects: The 2017 Revision I Multimedia Library United Nations Department of Economic and Social Affairs. In: UN Dep Econ Soc Aff. https:// www.un.org/development/desa/publications/world-population-prospects-the-2017-revision. html. Accessed 13 Jun 2018

United Nations General Assembly (2015) Transforming our world: the 2030 Agenda for Sustainable Development

Vanham D, Mekonnen MM, Hoekstra AY (2013) The water footprint of the EU for different diets. Ecol Indic 32:1-8. https://doi.org/10.1016/j.ecolind.2013.02.020

Webber CB, Sarjahani A (2011) Fitting sustainable food systems into dietetic internships - a growing trend. J Hunger Environ Nutr 6:477-489. https://doi.org/10.1080/19320248.2011.627304

Wegener J (2018) Equipping future generations of registered dietitian nutritionists and public health nutritionists: a commentary on education and training needs to promote sustainable food systems and practices in the 21st century. J Acad Nutr Diet 118:393. https://doi.org/10.1016/j. jand.2017.10.024

\section{Suggested Readings}

Food Climate Research Network's Foodsource: Evidence-based resources on SFS. Foodsource's purpose is to build the foundations for this understanding and for change towards more SFS, by increasing food systems literacy

Mason P, Lang T (2017b) Sustainable diets: how ecological nutrition can transform cosumption and the food system. Earthscan, Abingdon 